\title{
Use of Gold Markers for Setup in Image-Guided Fractionated High-Dose-Rate Brachytherapy as a Monotherapy for Prostate Cancer
}

\author{
Pirus Ghadjar ${ }^{1,2}$, Nicole Gwerder ${ }^{1}$,Axel Madlung ${ }^{1}$, Frank Behrensmeier', George N. Thalmann², \\ Roberto Mini', Daniel M. Aebersold ${ }^{1}$
}

\begin{abstract}
Background and Purpose: In order to use a single implant with one treatment plan in fractionated high-dose-rate brachytherapy (HDR-B), applicator position shifts must be corrected prior to each fraction. The authors investigated the use of gold markers for X-ray-based setup and position control between the single fractions.

Patients and Methods: Caudad-cephalad movement of the applicators prior to each HDR-B fraction was determined on radiographs using two to three gold markers, which had been inserted into the prostate as intraprostatic reference, and one to two radiopaque-labeled reference applicators. 35 prostate cancer patients, treated by HDR-B as a monotherapy between 10/2003 and $06 / 2006$ with four fractions of $9.5 \mathrm{~Gy}$ each, were analyzed. Toxicity was scored according to the CTCAE Score, version 3.0. Median follow-up was 3 years.

Results: The mean change of applicators positions compared to baseline varied substantially between HDR-B fractions, being $1.4 \mathrm{~mm}$ before fraction 1 (range, -4 to $2 \mathrm{~mm}$ ), $-13.1 \mathrm{~mm}$ before fraction 2 (range, -36 to $0 \mathrm{~mm}$ ), $-4.1 \mathrm{~mm}$ before fraction 3 (range, -21 to $9 \mathrm{~mm}$ ), and $-2.6 \mathrm{~mm}$ at fraction 4 (range, -16 to $9 \mathrm{~mm}$ ). The original position of the applicators could be readjusted easily prior to each fraction in every patient. In 18 patients (51\%), the applicators were at least once readjusted $>10 \mathrm{~mm}$, however, acute or late grade $\geq 2$ genitourinary toxicity was not increased $(p=1.0)$ in these patients.

Conclusion: Caudad position shifts up to $36 \mathrm{~mm}$ were observed. Gold markers represent a valuable tool to ensure setup accuracy and precise dose delivery in fractionated HDR-B monotherapy of prostate cancer.
\end{abstract}

Key Words: Gold markers · IGRT · HDR-B · Monotherapy $\cdot$ Prostate cancer

Strahlenther Onkol 2009;185:731-5

DOI 10.1007/s00066-009-2007-7

\section{Nutzen von Goldmarkern zur Konfiguration bei der bildgestützten, fraktionierten High-Dose-Rate-Brachytherapie als Monotherapie des Prostatakarzinoms}

Hintergrund und Ziel: Um ein einziges Implantat mit einem Bestrahlungsplan für die fraktionierte High-Dose-Rate-Brachytherapie (HDR-B) nutzen zu können, müssen Positionsverschiebungen der Katheter vor jeder Fraktion erkannt und korrigiert werden. Die Autoren untersuchten den Nutzen von Goldmarkern für röntgenbildbasierte Konfiguration und Positionskontrolle zwischen den Einzelfraktionen.

Patienten und Methodik: Die kraniokaudalen Verschiebungen der Applikatoren wurden vor jeder HDR-B-Fraktion anhand von zwei bis drei Goldmarkern als intraprostatische Referenz und ein bis zwei röntgendicht markierten Referenzapplikatoren mittels Röntgenbild bestimmt. 35 Patienten mit Prostatakarzinom, welche zwischen 10/2003 and 06/2006 eine HDR-B als Monotherapie mit vier Fraktionen von jeweils 9,5 Gy erhielten, wurden untersucht. Die Behandlungstoxizität wurde mit dem CTCAE-Score, Version 3.0, erfasst. Die mediane Nachbeobachtungszeit lag bei 3 Jahren.

Ergebnisse: Die mittlere Positionsabweichung der Applikatoren von der Sollposition variierte erheblich zwischen den HDR-B-Fraktionen und betrug 1,4 mm vor der ersten Fraktion (Spannweite: -4 bis $2 \mathrm{~mm}$ ), $-13,1 \mathrm{~mm}$ vor der zweiten Fraktion (Spannweite: -36 bis $0 \mathrm{~mm}$ ), $-4,1 \mathrm{~mm}$ vor der dritten Fraktion (Spannweite: -21 bis $9 \mathrm{~mm}$ ) und $-2,6 \mathrm{~mm}$ vor der vierten Fraktion (Spannweite: -16 bis $9 \mathrm{~mm}$ ). Die ursprüngliche Position der Applikatoren konnte bei jedem Patienten problemlos vor jeder Fraktion wiederhergestellt werden. Bei 18 Patienten (51\%) wurden die Applikatoren wenigstens einmal > $10 \mathrm{~mm}$ verschoben; dennoch war die genitourethrale Akut- oder Spättoxizität Grad $\geq 2$ bei diesen Patienten nicht erhöht $(p=1,0)$.

\footnotetext{
${ }^{1}$ Department of Radiation Oncology with Division of Medical Radiation Physics, Inselspital, Bern University Hospital, and University of Bern, Switzerland, ${ }^{2}$ Department of Urology, Inselspital, Bern University Hospital, and University of Bern, Switzerland.
} 
Schlussfolgerung: Positionsverschiebungen von bis zu $36 \mathrm{~mm}$ nach kaudal wurden beobachtet. Goldmarker sind bei der fraktionierten HDR-B-Monotherapie des Prostatakarzinoms von Nutzen, um die akkurate Konfiguration und die präzise Verabreichung der Strahlendosis zu gewährleisten.

Schlüsselwörter: Goldmarker · IGRT · HDR-B · Monotherapie · Prostatakarzinom

\section{Introduction}

Prostate cancer (PCA) as the most commonly diagnosed cancer among men in Europe and North America [2,15] after skin cancer has various treatment possibilities. For patients with low- and intermediate-risk PCA active surveillance, radical prostatectomy, external-beam radiation therapy (EBRT), low-dose-rate brachytherapy (LDR-B) and high-dose-rate brachytherapy (HDR-B) are arguable treatment options. Several reports on HDR-B in combination with EBRT have been published $[1,5,7,9,13,17,19,21]$, but HDR-B as a monotherapy is a relatively new approach. Different fractionation schedules are described in the literature with the single dose ranging from 6 to 10.5 Gy and the number of fractions ranging from three to nine with a minimum interval of $6 \mathrm{~h}$ between the subsequent fractions. Generally, for logistic and economic reasons one implant and one treatment plan are used [4, 10, 11, 16, 18, 25-27]. However, there are no standard criteria or guidelines for repeating imaging and dosimetry for each fraction after a single implant. Martinez et al. were the first to introduce a fractionation scheme with four single fractions of $9.5 \mathrm{~Gy}$ each [18], which was adopted by us and others $[10,16]$. In their pioneering report, they described the caudad-cephalad movement of the applicators prior to each fraction in a subgroup of their patients. The mean applicator movement peaked before the second fraction being $20 \mathrm{~mm}$ (range, 10-31 mm) in the caudad direction which was measured by fluoroscopy after filling the bladder with contrast material. Given the typical HDR-B treatment length of $35-50 \mathrm{~mm}$, it is obvious that applicator dislocations of $>10 \mathrm{~mm}$ may have a devastating impact on the accurate treatment delivery of subsequent fractions if only one implant and one treatment plan are used. It is therefore fundamental to detect and correct these dislocations prior to each fraction.

In this study, we have investigated the use of gold markers for a simple X-ray-based setup and position control between the single fractions in HDR-B monotherapy for PCA. Feasibility of this approach, direction and magnitude of the dislocations between the fractions, as well as their associations with the acute and late genitourinary (GU) toxicity are reported.

\section{Patients and Methods}

Patient Selection, Characteristics, and Implant

A total of 36 patients with histologically proven adenocarcinoma of the prostate were treated by HDR-B as a mono- therapy between 10/2003 and 06/2006, as previously described [10]. Briefly, these patients were staged according to the 2002 American Joint Committee on Cancer tumor, lymph nodes and metastasis system [24].

All patients received one implant and four separate fractions of HDR-B delivered within 48 h. Fraction dose was 9.5 Gy, the total prescribed dose was 38 Gy. The minimal interval between fractions was $6 \mathrm{~h}$. For the implantation of the applicators, patients underwent spinal anesthesia and were placed in lithotomy position. The applicators were implanted by an urologist by transperineal placement under real-time transrectal ultrasound (TRUS) guidance using a template for parallel needle insertion. Patients received a variable number of needles depending on the prostate size and configuration. Axial cross sections were acquired in 5-mm steps and transferred to the Plato ${ }^{\circledR}$ treatment-planning software (Nucletron, Veenendaal, The Netherlands). Dose optimization was done on the reconstructed applicator geometry using dose point and manual optimization algorithms.

After implantation of the applicators, patients received two to three gold markers (diameter: $0.9 \mathrm{~mm}$, length: $7 \mathrm{~mm}$ ), implanted under TRUS guidance. One to two applicators served as reference being visualized on the X-ray by insertion of a radiopaque dummy wire. A reference X-ray was taken in anterior-posterior direction right after the correct position of the catheters had been confirmed by ultrasound at the end of the implantation. Applicators were then sutured to the perineum. X-rays were taken before the first, second, third, and fourth fraction. In case of dislocation $>2 \mathrm{~mm}$ all applicators were replaced until complete agreement was found with the reference X-ray. X-rays were analyzed retrospectively and the incidence and the magnitude of applicator dislocations were recorded. One patient was excluded because the radiographs were not available; thus, the study population consisted of 35 patients. Patients were grouped according to their risk of recurrence according to the National Comprehensive Cancer Network practice guidelines in oncology (http:// www.nccn.org). 27 patients were classified as low risk (77\%) and eight patients as high risk (23\%). Patients' median age was 64 years (range, 46-81 years). The median follow-up was 3 years (range, 0.4-4.0 years). Patients received a mean number of 13.6 applicators (range, 10-18 applicators) representing a total of 475 applicators. For irradiation, a high-dose-rate afterloading system (Nucletron) with a ${ }^{192}$ Ir stepping source was used. This study was approved by the institutional ethics committee. 


\section{Follow-Up Protocol, Toxicity Scoring, and Biochemical Failure}

Patients were seen by a radiation oncologist twice daily during the radiation monotherapy. Follow-up visits were arranged 2-4 weeks after completion of HDR-B, every 3-6 months for the first 2 years, and annually thereafter with a digital-rectal examination and a serum prostate-specific antigen (PSA) level obtained at each visit. Patients alternated follow-up visits between their urologist and radiation oncologist. None of the patients were lost to follow-up.

The symptoms dysuria, incontinence, retention, frequency/urgency, and hematuria were graded using the common terminology criteria for adverse events from the National Cancer Institute (CTCAE version 3.0; http://ctep.cancer.gov/ forms/CTCAEv3.pdf). Late toxicity was defined as complications occurring within 3 months after the end of treatment.

Table 1. Observed interfractional applicator shifts.-: shift in the caudal direction; +: shift in the cephalad direction.

Tabelle 1. Beobachtete Applikatorverschiebungen zwischen den Fraktionen.-:Verschiebung in die kaudale Richtung; +:Verschiebung in die kraniale Richtung

\begin{tabular}{lc}
\hline & $\begin{array}{l}\text { Mean and median applicator dislocations } \\
\text { range }(\mathbf{m m})\end{array}$ \\
\hline Before fraction 1 & +1.4 and $0(-4$ to +2$)$ \\
Before fraction 2 & -13.1 and $-11(-36$ to 0$)$ \\
Before fraction 3 & -4.1 and $-2(-21$ to +9$)$ \\
Before fraction 4 & -2.6 and $-2(-16$ to +9$)$ \\
\hline
\end{tabular}
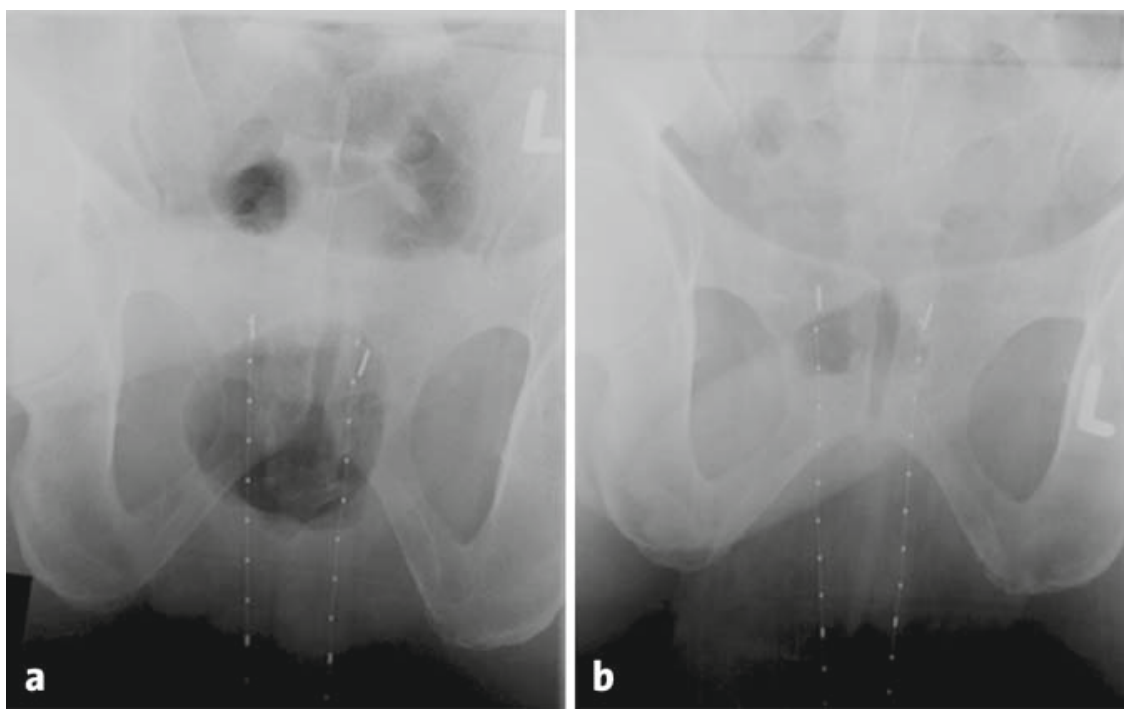

Figures $\mathbf{1 a}$ and $\mathbf{1} \mathbf{b}$. The reference $X$-ray showing the position of two reference catheters relative to the two implanted gold markers (a). Before the second fraction, both catheters are dislocated caudally, with a maximal magnitude of $10 \mathrm{~mm}(\mathrm{~b})$.

Abbildungen 1a und $\mathbf{1 b}$. Das Referenzröntgenbild zeigt die Position der beiden Referenzkatheter relativ zu den zwei implantierten Goldmarkern (a). Vor der zweiten Fraktion sind beide Katheter nach kaudal disloziert, mit einer maximalen Verschiebung von $10 \mathrm{~mm}$ (b).
Biochemical no evidence of disease (bNED) was assessed according to the Phoenix criteria, defining a biochemical failure as a PSA rise of $\geq 2 \mathrm{ng} / \mathrm{ml}$ above the nadir PSA [23].

\section{Statistical Analysis}

The primary endpoint was the occurrence of interfractional applicator dislocation $>10 \mathrm{~mm}$ and the secondary endpoint was the occurrence of acute or late grade $\geq 2$ GU toxicity. Acute and late (grade $0-1$ vs. grade $2-3$ ) GU toxicities were grouped and compared with occurrence of interfractional applicator dislocation $>10 \mathrm{~mm}$ using Fisher's exact test. Interfractional applicator dislocation $>10 \mathrm{~mm}$ was compared with the size of the planning target volume (PTV) and the number of needles using the Mann-Whitney U-test. Statistical significance was considered on a two-sided significance level $(\alpha)$ of $=0.05$. Statistical analysis was performed with SPSS version 16.0 (SPSS Inc., Chicago, IL, USA).

\section{Results}

\section{Direction and Magnitude of Applicator Dislocations}

17 patients (49\%) had received two and 18 patients (51\%) had received three gold markers as intraprostatic reference. In nine patients $(26 \%)$, one radiopaque-labeled reference applicator and in 26 patients $(74 \%)$, two reference applicators were used.

Dislocations of the applicators $>2 \mathrm{~mm}$ were observed at least once in 32 out of 35 patients $(91 \%)$, with the total number of dislocations $>2 \mathrm{~mm}$ being 69,63 of which where dislocations in the caudal direction (91\%). Interestingly, the six observed dislocations in the cephalad direction occurred only before the third $(\mathrm{n}=3)$ and the fourth $(\mathrm{n}=3)$ fraction. Mean and median dislocations and ranges between the fractions are summarized in Table 1. Before the first fraction, correction of the catheter position was performed in one patient. Before the second, third, and fourth fraction, corrections were performed in 30,19 , and 19 patients, respectively (Figure 1). Dislocations of the applicators $>10 \mathrm{~mm}$ were at least once observed in 18 out of 35 patients (51\%). Corrections $>10$ $\mathrm{mm}$ were not necessary before the first fraction but were performed in 18 , four, and two patients before the second, third, and fourth fraction, respectively. Dislocations of the applicators $>20 \mathrm{~mm}$ were at least once observed in seven out of 35 patients $(20 \%)$. Corrections $>20$ $\mathrm{mm}$ were performed in six and one patient before the second and third fraction, respectively. However, the original position of the applicators could be 
readjusted easily prior to each fraction in every patient and HDR-B was carried out as scheduled. After readjustment of the applicators, there were no position shifts in left-right direction observed. A new treatment plan was not required in any patient.

Correction of Applicator Dislocation and Treatment Toxicity After treatment, acute grade 1,2, or 3 GU toxicity occurred in $15(43 \%), 14(40 \%)$, and one (3\%) patients, respectively. Late grade 1,2 , and $3 \mathrm{GU}$ toxicity occurred in twelve (34\%), eight (23\%), and four (11\%) patients, respectively.

Occurrence of applicator dislocation $>10 \mathrm{~mm}$ and their subsequent correction were not associated with increased acute or late grade $\geq 2$ GU toxicity (both, $\mathrm{p}=1.0$ ).

Further, occurrence of applicator dislocation $>10 \mathrm{~mm}$ was not associated with the PTV size $(p=0.86)$ nor with the number of needles used ( $\mathrm{p}=0.98)$.

Overall survival and biochemical control of patients after 3 years was $100 \%$; thus, no association with the occurrence of applicator dislocations could be determined.

\section{Discussion}

If radiotherapy is chosen for treatment of PCA, dose-escalated intensity-modulated radiation therapy is often considered the gold standard treatment for all risk groups [12, 22]. However, due to the very low $\alpha / \beta$ ratio of 1.5 Gy of PCA $[3,6,8]$ which makes the cancer cells sensitive to hypofractionation, HDR-B may play a more dominant role in the treatment of PCA in the future. While HDR-B is widely used as a boost to EBRT, the use of HDR-B as a monotherapy for PCA remains experimental. The $4 \times 9.5$ Gy schedule for HDR-B as a monotherapy of low-risk patients was introduced by Martinez et al. [18]. Before each fraction, the bladder was filled with contrast material and fluoroscopy was performed to record the relationship of the tip of the needles to the bony anatomy and the bladder base. Any applicator movement in the caudad-cephalad direction was noted and corrected under fluoroscopy. For ten patients the mean interfractional movement was described which peaked before the second fraction being $20 \mathrm{~mm}$ (range, 10-31 mm) in the caudad direction. Moreover, Martinez et al. showed an increase of the prostate volume of approximately $20 \%$ after insertion of the needles, probably related to prostatic bleeding and/or edema. However, during the subsequent $32-36 \mathrm{~h}$ the prostate volume did not differ substantially. The $4 \times 9.5$ Gy fractionation scheme has also been used by Martin et al. [16]. In their report, they stated that needle movement in the caudad-cephalad direction was controlled, however, details concerning the technique which was therefore used are lacking. The effectiveness of HDR-B monotherapy in intermediate- and even high-risk PCA has been shown by Yoshioka et al., using higher doses with a total dose up to 54 Gy delivered in eight to nine fractions of $6 \mathrm{~Gy}$ with the patients restricted to bed for 5 days [25-27]. However, details concerning the control of interfractional applicator motion are lacking. One phase II dose-escalation study by Hoskin et al. has compared HDR-B monotherapy with 34 Gy in four fractions, 36 Gy in four fractions, and 31.5 Gy in three fractions [14]. Computed tomography was performed before the second and fourth fraction and catheters were readjusted if they were dislocated $>5 \mathrm{~mm}$ [14]. We have used the $4 \times 9.5$ Gy fractionation scheme with ultrasound-based postplanning. Gold markers and radiopaquelabeled reference applicators were used for X-ray-based setup and position control between the single fractions. Toxicity rates have been previously described [10], being comparable to the two existing studies using the same fractionation schedule $[16,18]$. We observed substantial interfractional applicator dislocations, predominantly in the caudad direction, peaking before the second fraction, with the mean value being $-13.1 \mathrm{~mm}$ (range, -36 to $0 \mathrm{~mm}$ ). This can be explained by the postimplant prostate bleeding and/or edema with enlargement of the prostate as it has been described by others [18]. Prostate edema, subsequent prostate volume changes, and changes of dosimetric parameters after LDR-B were extensively described [20]. In our study, dislocations of the applicators $\leq 2 \mathrm{~mm}$ were tolerated, dislocations $>2 \mathrm{~mm}$ were corrected. This is a relatively low action level. Thus, applicators had to be readjusted in $91 \%$ of the patients. Since readjustment of the applicators requires intraprostatic manipulation which could potentially be associated with a trauma to the prostate, urethra or bladder, we were interested if readjustments $>10 \mathrm{~mm}$ were associated with increased GU toxicity. However, we found no association with acute or late GU toxicity. Moreover, there was no association with the PTV size or the number of needles used. One limitation of our study is the relatively short median follow-up with no patient experiencing biochemical relapse. If the follow-up matures, it will be interesting to compare the biochemical outcome data with incidence and magnitude of applicator dislocations to exclude insufficient PTV dose covering.

The consistency of the implant geometry between HDR-B fractions is of utmost importance for an appropriate dose delivery. Novel approaches such as real-time online planning have facilitated repetitive planning procedures, but are still laborious and time-consuming. We consider the use of gold markers for X-ray-based setup and position control between the single fractions a feasible and valuable tool for fractionated HDR-B of the prostate.

\section{References}

1. Aebersold DM, Isaak B, Thalmann G, et al. Applicability and dosimetric impact of ultrasound-based preplanning in high-dose-rate brachytherapy of prostate cancer. Strahlenther Onkol 2004;180:351-7.

2. Bracarda S, de Cobelli 0 , Greco $C$, et al. Cancer of the prostate. Crit Rev Oncol Hematol 2005;56:379-96.

3. Brenner DJ, Hall EJ. Fractionation and protraction for radiotherapy of prostate carcinoma. Int J Radiat Oncol Biol Phys 1999;43:1095-101.

4. Corner C, Rojas AM, Bryant L, et al. A phase II study of high-dose-rate afterloading brachytherapy as monotherapy for the treatment of localized prostate cancer. Int J Radiat Oncol Biol Phys 2008;72:441-6. 
5. Demanes DJ, Rodriguez RR, Schour L, et al. High-dose-rate intensity-modulated brachytherapy with external beam radiotherapy for prostate cancer: California endocurietherapy's 10 year results. Int J Radiat Oncol Biol Phys 2005;61:1306-16.

6. Dörr W, Jaal J, Zips D. Prostate cancer: biological dose considerations and constraints in tele- and brachytherapy. Strahlenther Onkol 2007;183:14-5.

7. Eulau SM, Van Hollebeke L, Cavanagh W, et al. High dose rate iridium 192 brachytherapy in localized prostate cancer: results and toxicity with maximum follow-up of 10 years. Int J Radiat Oncol Biol Phys 2000;48: Suppl:149.abstract.

8. Fowler JF. The linear-quadratic formula and progress in fractionated radiotherapy. Br J Radiol 1989;62:679-94.

9. Galalae RM, Martinez A, Mate T, et al. Long-term outcome by risk factors using conformal high-dose-rate brachytherapy (HDR-BT) boost with or without neoadjuvant androgen supression for localized prostate cancer. Int J Radiat Oncol Biol Phys 2004;58:1048-55.

10. Ghadjar P, Keller T, Rentsch CA, et al. Toxicity and early treatment outcomes in low- and intermediate-risk prostate cancer managed by high-dose-rate brachytherapy as a monotherapy. Brachytherapy 2009;8:45-51.

11. Grills IS, Martinez AA, Hollander M, et al. High dose rate brachytherapy as prostate cancer monotherapy reduces toxicity compared to low dose rate palladium seeds. J Urol 2004;171:1098-104.

12. Guckenberger M, Flentje M. Intensity-modulated radiotherapy (IMRT) of localized prostate cancer: a review and future perspectives. Strahlenther Onkol 2007;183:57-62.

13. Hiratsuka J, Jo Y, Yoshida K, et al. Clinical results of combined treatment conformal high-dose-rate iridium-192 brachytherapy and external beam radiotherapy using staging lymphadenectomy for localized prostate cancer. Int J Radiat Oncol Biol Phys 2004;59:684-90.

14. Hoskin PJ, Brownes PJ, Ostler P, et al. High dose rate afterloading brachytherapy for prostate cancer: catheter and gland movement between fractions. Radiother Oncol 2003;68:285-8.

15. Jemal A, Siegel R, Ward E, et al. Cancer statistics, 2006. CA Cancer J Clin 2006;56:106-30.

16. Martin T, Baltas D, Kurek R, et al. 3-D conformal HDR brachytherapy as monotherapy for localized prostate cancer. A pilot study. Strahlenther Onkol 2004;180:225-32.

17. Martinez AA, Gustafson G, Gonzalez J, et al. Dose escalation using conformal high-dose-rate brachytherapy improves outcome in unfavorable prostate cancer. Int J Radiat Oncol Biol Phys 2002;53:316-27.

18. Martinez AA, Pataki I, Edmundson G, et al. Phase II prospective study of the use of conformal high-dose-rate brachytherapy as monotherapy for the treatment of favorable stage prostate cancer: a feasibility report. Int J Radiat Oncol Biol Phys 2001;49:61-9.

19. Pellizzon AC, Nadalin W, Salvajoli JV, et al. Results of high dose rate afterloading brachytherapy boost to conventional external beam radiation therapy for initial and locally advanced prostate cancer. Radiother Oncol 2003;66:167-72.

20. Pinkawa M, Gagel B, Piroth MD, et al. Changes of dose delivery distribution within the first month after permanent interstitial brachytherapy for prostate cancer. Strahlenther Onkol 2006;182:525-30.

21. Rades D, Schwarz R, Todorovic $M$, et al. Experiences with a new high-dose-rate brachytherapy (HDR-BT) boost technique for T3b prostate cancer. Strahlenther Onkol 2007;183:398-402.

22. Roach M 3rd. Dose escalated external beam radiotherapy versus neoadjuvant androgen deprivation therapy and conventional dose external beam radiotherapy for clinically localized prostate cancer: do we need both? Strahlenther Onkol 2007; Special issue 2:183:26-28.

23. Roach M 3rd, Hanks G, Thames $\mathrm{H} \mathrm{Jr}$, et al. Defining biochemical failure following radiotherapy with or without hormonal therapy in men with clinically localized prostate cancer: recommendations of the RTOG-ASTRO Phoenix consensus conference. Int J Radiat Oncol Biol Phys 2006;65:965-74.

24. Sobin LH, Wittekind CH. The prostate. In: Sobin LH, Wittekind CH, eds. TNM classification of malignant tumors. New York: Wiley-Liss, 2002:184-7.

25. Yoshioka Y, Konishi K, Oh RJ, et al. High-dose-rate brachytherapy without external beam irradiation for locally advanced prostate cancer. Radiother Oncol 2006;80:62-8.

26. Yoshioka Y, Nose T, Yoshida K, et al. High-dose-rate interstitial brachytherapy as a monotherapy for localized prostate cancer: treatment description and preliminary results of a phase I/II clinical trial. Int J Radiat Oncol Biol Phys 2000;48:675-81.

27. Yoshioka Y, Nose T, Yoshida K, et al. High-dose-rate brachytherapy as monotherapy for localized prostate cancer: a retrospective analysis with special focus on tolerance and chronic toxicity. Int J Radiat Oncol Biol Phys 2003;56:213-20.

\author{
Address for Correspondence \\ Prof. Dr. Daniel M. Aebersold \\ Department of Radiation Oncology \\ Inselspital \\ Bern University Hospital, \\ Freiburgstraße \\ 3011 Bern \\ Switzerland \\ Phone (+41/31) 632-2431, Fax -382-2342 \\ e-mail: daniel.aebersold@insel.ch
}

